\title{
Synergistic therapeutic effects of cytokine-induced killer cells and temozolomide against glioblastoma
}

\author{
JUYOUN JIN ${ }^{1,2^{*}}$, KYEUNG MIN JOO ${ }^{2,3^{*}}$, SE JEONG LEE ${ }^{1,2}$, MI-YOUNG JO ${ }^{1,2}$, \\ YONGHYUN KIM ${ }^{1,2}$, YOUNGGEON JIN ${ }^{1,2}$, JOONG KYU KIM ${ }^{2}$, JI MI AHN ${ }^{4}$, \\ MI-JUNG YOON ${ }^{4}$, JAESEUNG LIM ${ }^{4}$ and DO-HYUN NAM ${ }^{1,2^{*}}$
}

\begin{abstract}
${ }^{1}$ Department of Neurosurgery, ${ }^{2}$ Cancer Stem Cell Research Center, Samsung Medical Center and Samsung Biomedical Research Institute, Sungkyunkwan University School of Medicine, \#50 Irwon-dong, Gangnam-Gu, Seoul 135-710; ${ }^{3}$ Department of Anatomy, Seoul National University College of Medicine, \#28 Yeongeon-dong, Jongno-gu, Seoul 110-799; ${ }^{4}$ Innocell Corporation, SJ Technoville, 60-19 Gasandong, Geumcheongu, Seoul 153-769, Korea
\end{abstract}

Received March 1,2010; Accepted April 22, 2010

DOI: 10.3892/or_00001038

\begin{abstract}
The presence of active immunity within the brain supports the possibility of effective immunotherapy for glioblastoma (GBM). To provide a clinically-relevant adoptive immunotherapy for GBM using ex vivo expanded cytokineinduced killer (CIK) cells, the treatment capability of CIK cells, either alone or in combination with temozolomide (TMZ) were evaluated. Human CIK (hCIK) cells were cultured from PBMC using activating anti-CD3 antibody and IL-2, which were $99 \% \mathrm{CD}^{+}, 91 \% \mathrm{CD}^{+}{ }^{+} \mathrm{CD} 8^{+}$and $29 \%$ $\mathrm{CD}^{+}{ }^{+} \mathrm{CD}^{2} 6^{+}$. In vitro, hCIK cells showed tumor-specific cytotoxicity against U-87MG human GBM cells. When hCIK cells were injected into tail veins of immune-compromised mice bearing U-87MG tumors in their brains, numerous CIK cells infiltrated into the brain tumors. CIK treatments $\left(1 \times 10^{5}\right.$, $1 \times 10^{6}$ or $1 \times 10^{7}$, once a week for four weeks) inhibited the tumor growth significantly in a dose-dependent manner; 44 , 54 and $72 \%$ tumor volume reduction, respectively, compared with the control group $(\mathrm{P}<0.05)$. Moreover, hCIK cells $\left(1 \times 10^{7}\right.$, once a week for four weeks) and TMZ $(2.5 \mathrm{mg} / \mathrm{kg}$, daily for 5 days) combination treatment further increased tumor cell apoptosis and decreased tumor cell proliferation and vessel density $(\mathrm{P}<0.05)$, creating a more potent therapeutic effect (95\% reduction in tumor volume) compared with either hCIK cells or TMZ single therapy $(72 \%$ for both, $\mathrm{P}<0.05)$. Taken together, CIK cell-immunotherapy and TMZ chemotherapy
\end{abstract}

Correspondence to: Dr Do-Hyun Nam, Department of Neurosurgery, Samsung Medical Center and Biomedical Research Institute, Sungkyunkwan University School of Medicine, \#50 Irwon-dong, Gangnam-gu, Seoul 135-710, Korea

E-mail: nsnam@skku.edu

${ }^{*}$ Contributed equally

Key words: cytokine-induced killer cells, adoptive immunotherapy, themozolomide, glioblastoma, orthotopic animal model have synergistic therapeutic effects and could be combined for a successful treatment of GBM.

\section{Introduction}

Glioblastoma (GBM) is the most common primary malignant brain tumor. Despite multidisciplinary treatment approaches, prognosis and survival for patients with GBM remains poor (1). Traditionally, the brain has long been considered as an immunologically privileged organ because of the blood-brain barrier (2). However, increased awareness of the interplay between the brain and the immune system (3) and the presence of active immunity within the brain support the possibility of effective immunotherapy for GBM.

The goal of immune cell-based cancer therapy is to eliminate cancer cells through the transfer of ex vivo expanded active immune cells. Various immune cell types such as dendritic cells, lymphokine-activated killer (LAK) cells, natural killer (NK) cells, cytotoxic T cells and cytokineinduced killer (CIK) cells have been studied as a potential candidate for effective immunotherapy (4-8). Among them, CIK cells, characterized by the co-expression of CD3 and CD56 molecules, demonstrated potent cytolytic activity in a MHC-unrestricted manner (4,5). In addition, CIK cells are most clinically applicable since CIK cells are readily expandable from peripheral blood mononuclear cells (PBMC) of cancer patients (6).

Two previous studies showed that CIK cells have significant therapeutic effects against GBM in vivo $(7,8)$. However, intracranial CIK cell injection method (7) and results from subcutaneous GBM xenograft animal model (8) are difficult to translate immediately into the clinical settings. Combinational effects with temozolomide (TMZ) also need to be considered since it is the most widely-used chemotherapeutic agent against GBM in the clinic. Accordingly, we utilized U-87MG GBM orthotopic xenograft animal models and evaluated anti-tumor effects of CIK cells with intravenous injection. CIK cells showed significant therapeutic effects against GBM, and it was potentiated by the combination with TMZ. 
A

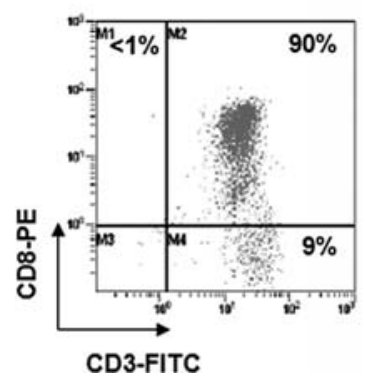

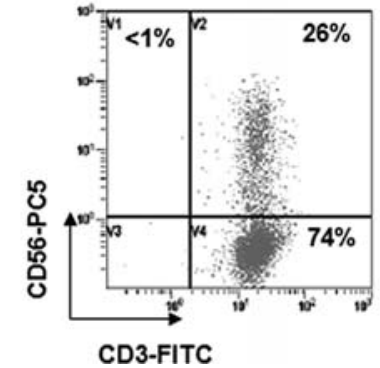

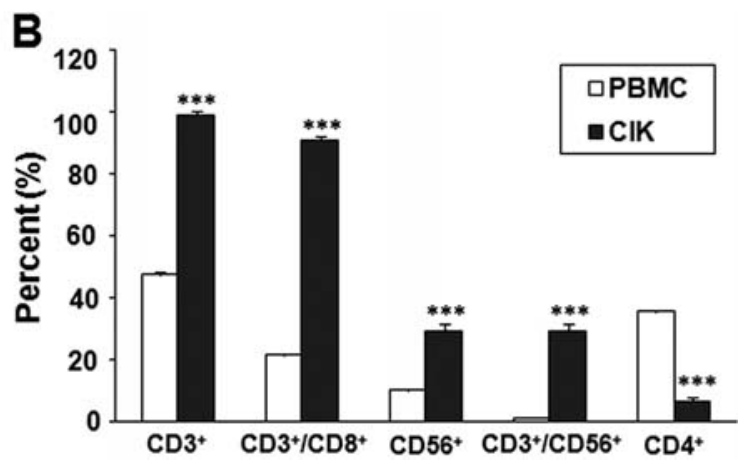

Figure 1. Molecular characteristics of hCIK cells. (A) CD3, CD8 and CD56 expression of cultured hCIK cells were analyzed by flow cytometry. (B) Phenotypes of fresh PBMC and CIK cells were compared. Data are expressed as the mean \pm SE of eight separate experiments. ${ }^{* * *} \mathrm{P}<0.001$.

\section{Materials and methods}

Generation of human and mouse CIK cells. Human cytokineinduced killer (hCIK) cells were generated from PBMC of healthy donors (8-12). PBMC cultured in lymphomedia (Lymphotech, Japan) containing 10\% FBS (Invitrogen, CA, USA), immobilized anti-CD 3 antibody ( $5 \mathrm{mg} / \mathrm{ml}, \mathrm{BD}$ Pharmingen, NJ, USA) and recombinant human interleukin-2 (IL-2; $700 \mathrm{U} / \mathrm{ml}, \mathrm{R} \& \mathrm{D}$ Systems, MN, USA) for five days. The cell suspension were further incubated in a fresh media containing only recombinant human IL-2 $(170 \mathrm{U} / \mathrm{ml})$ for nine days. Mouse CIK (mCIK) cells were generated from spleens of GFP transgenic C57BL/6 mouse [C57BL/6-Tg (UBC-GFP) $30 \mathrm{Scha} / \mathrm{J}$, The Jackson Laboratory, Bar Harbor, ME] (13). Expansion of mCIK cells was performed as described above.

Phenotype analysis of human and mouse CIK cells. Fresh PBMC and expanded hCIK cells were analyzed with appropriate monoclonal antibodies (CD3-FITC, CD4-FITC, CD8-PE, CD56-PC5 and CD25-PE, Beckman Coulter, Fullerton, USA). Fluorescence-activated cell sorting analyses was performed on a FACS Calibur flow cytometer (BD Biosciences, CA, USA) as described previously $(8,10-12)$. mCIK phenotype analysis was performed in a similar manner using CD3-PerCP, CD4-FITC, CD8-PE, NKG2D-PECy7, and CD25-PE (BD Pharmingen).

Cell culture. U-87MG human GBM cells (ATCC) were grown in EMEM supplemented with 10\% FBS, 2 mM L-glutamine, penicillin $(100 \mathrm{U} / \mathrm{ml})$, and streptomycin $(100 \mu \mathrm{g} / \mathrm{ml})$. The murine GBM cell line GL26 (H-2b) was kindly provided by Dr John S. Yu (Cedars Sinai Medical Center, Los Angeles, CA, USA). GL26 cells were cultured in RPMI-1640 supplemented with $10 \%$ FBS.

In vitro cytotoxic activity of hCIK cells. The human cancer cell lysis by hCIK cells was detected by the release of lactate dehydrogenase (LDH) using CytoTox 96 non-radioactive cytotoxicity assay according to the manufacturer's instructions (Promega, USA) (14). Briefly, CIK cells were added at specified effector-to-target (E:T) ratios (10:1 to 30:1) and incubated for $4 \mathrm{~h}$. The absorbance was measured at $490 \mathrm{~nm}$ using a Multiscan MS microplate reader (LabSystem,

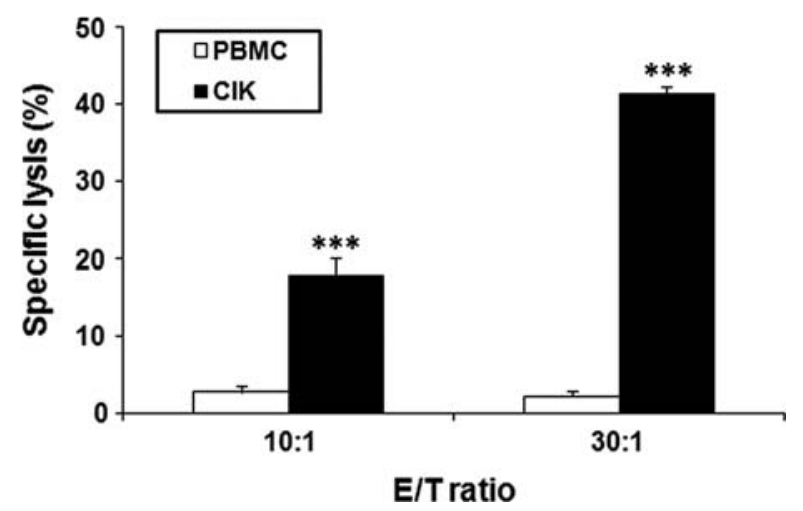

Figure 2. hCIK cells are cytotoxic against human GBM cells in vitro. U-87MG human GBM cells were incubated for $4 \mathrm{~h}$ with fresh PBMC or 14-day cultured hCIK cells (effector-to-target ratios $=10: 1$ or 30:1). Cytotoxicities of PBMC and hCIK cells were compared by the LDH assay. Data are expressed as the mean $\pm \mathrm{SE} .{ }^{* * *} \mathrm{P}<0.001$.

Helsinki, Finland). Specific cytotoxicity was calculated as in previous studies (14).

GBM orthotopic animal model. Animal experiments were approved by the appropriate Institutional Review Boards of the Samsung Medical Center (Seoul, Korea) and conducted in accord with the 'National Institute of Health Guide for the Care and Use of Laboratory Animals' (NIH publication no. 80-23, revised in 1996). For orthotopic GBM model, anesthetized 6-week-old male Balb/c-nu (for U-87MG human GBM cells) and C57BL/6 (H-2 ${ }^{b}$, for GL26 murine GBM cells) mice were secured in a rodent stereotactic frame. A hollow guide screw was implanted into a small drill hole made at $2 \mathrm{~mm}$ left and $1 \mathrm{~mm}$ anterior to the bregma, and $2 \times 10^{5} \mathrm{U}-87 \mathrm{MG}$ cells in $5 \mu 1$ HBSS or $1 \times 10^{5}$ GL26 cells were injected through this guide screw into the white matter at a depth of $2 \mathrm{~mm}$ [anterior/posterior (AP) $+0.5 \mathrm{~mm}$, medial/ lateral (ML) +1.7 mm, dorsal/ventral (DV) $-3.2 \mathrm{~mm}$ ].

In vivo anti-tumor activities of hCIK cells in an orthotopic xenograft model. hCIK cells $\left(1 \times 10^{5}, 1 \times 10^{6}\right.$ or $1 \times 10^{7}$, in $100 \mu \mathrm{l}$ HBSS) were injected intravenously into animals bearing U-87MG tumor in their brains once a week for four weeks (Fig. 4A). One day after the last injection of hCIK cells, 


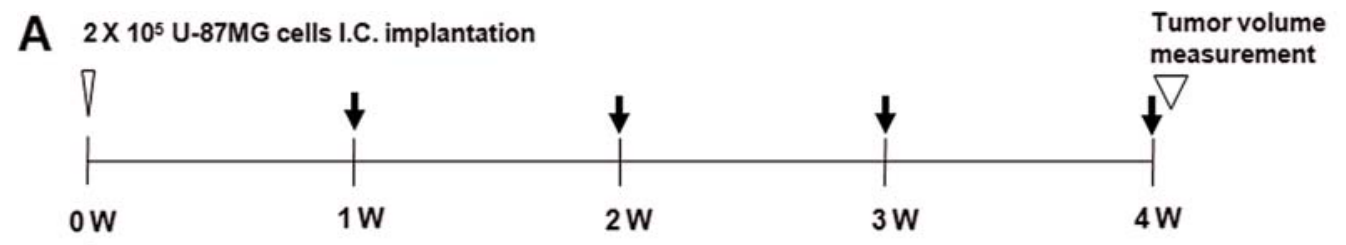

$\downarrow$ : Intravenous injection of $1 \times 10^{5}, 1 \times 10^{6}$, or $1 \times 10^{7} \mathrm{hClK}$ cells (in $100 \mu \mathrm{L}$ HBSS)

B control
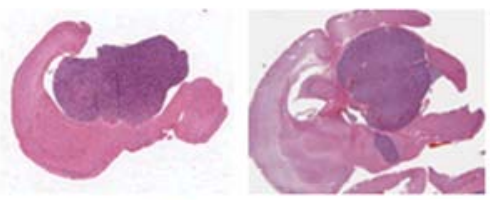

hCIK $1 \times 10^{5}$

C

hCIK $1 \times 10^{6}$
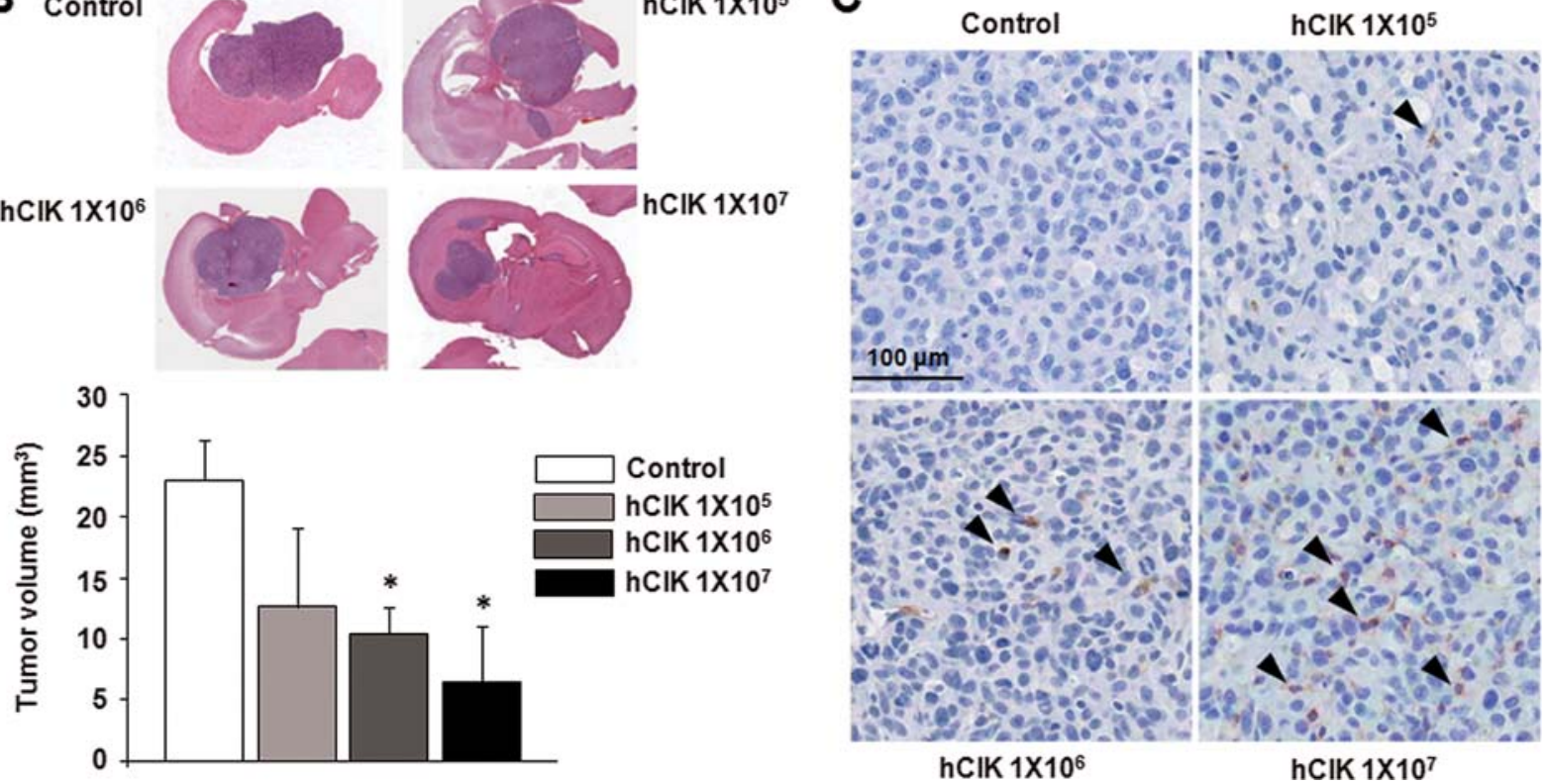

Figure 3. hCIK cells inhibit GBM tumor growth in an orthotopic xenograft model. (A) The timeline for the assessment of in vivo anti-tumor activities of hCIK cells in an orthotopic xenograft model. (B) hCIK cells reduced U-87MG tumor volumes in a dose-dependent manner. Data are expressed as the mean \pm SE. ${ }^{*} \mathrm{P}<0.05$. (C) hCIK cells were traced by immunohistochemistry using a human CD3 specific antibody. Arrowheads $=$ CD3-postive hCIK cells in the tumor bed.

brains were harvested and processed for paraffin embedding. The tumor volume was calculated by measuring the section with the largest tumor portion and applying the formula: (width) $)^{2}$ x length $x$ 0.5. For detection of hCIK cells in brain tumor sections, the mouse anti-human CD3 monoclonal antibody (Dako, USA) was used as the primary antibody (15).

In vivo tracking of $m C I K$ cells in an orthotopic syngenic model. GL26 tumor-bearing animals were injected with $1 \times 10^{8}$ of $\mathrm{GFP}^{+}$-mCIK cells (Fig. 3B). Two or nine days after the cell transfer, tumor-bearing mice were sacrificed and their blood, lymph node, spleen, lung, liver, brain and brain tumor were harvested. GFP-expressing cells were detected by FACS Calibur flow cytometer or immunohistochemistry using the mouse anti-GFP monoclonal antibody (Chemicon International, Temecula, CA) and the Alexa 488-labeled goat anti-mouse IgG (1:200, Invitrogen) (15).

In vivo therapeutic effects of combination treatment of $h C I K$ cells and TMZ in an orthotopic xenograft model. hCIK cells $\left(1 \times 10^{7}\right.$, in $\left.100 \mu 1 \mathrm{HBSS}\right)$ were injected intravenously into animals bearing U-87MG tumor in their brains once a week for four weeks, either alone or with intraperitoneal daily administration of $2.5 \mathrm{mg} / \mathrm{kg}$ TMZ (in $100 \mu \mathrm{l}$ saline) from 21 to 25 days after the tumor cell implantation (Fig. 5A). One day after the last injection, brains were harvested and processed for paraffin embedding. The tumor volume was calculated as described above.

Immunohistochemistry against PCNA and CD31 was performed as described previously (15). The mouse antiPCNA (PC10, Dako) and mouse anti-CD31/PECAM-1 (BD Pharmingen) antibody were utilized. TUNEL assay was performed by the DeadEnd fluorometric TUNEL system (Promega). For the quantification, the number of stained cells was counted in ten random fields for each animal.

Statistical analyses. Statistical comparisons between groups were performed using Student's t-test, one-way ANOVA or multiple comparison tests. $\mathrm{P}<0.05$ was considered statistically significant.

\section{Results}

In vitro expansion of $h C I K$ cells from human PBMC. hCIK cells cultured from human PBMC (hPBMC) using immobilized anti-CD3 antibody and recombinant human IL-2 for two weeks were $99 \% \mathrm{CD}^{+}, 91 \% \mathrm{CD}^{+} \mathrm{CD}^{+}$and $29 \% \mathrm{CD}^{+} \mathrm{CD}^{+} 6^{+}$ in flow cytometric analysis (Fig. 1A), which is consistent with the previous studies (10-12). Compared with fresh hPBMC, $\mathrm{CD}^{+} \mathrm{CD}^{+}$, and $\mathrm{CD} 3{ }^{+} \mathrm{CD}^{2} 6^{+}$cell ratio increased dramatically, while $\mathrm{CD}^{+}$cell ratio decreased $\left(^{* * *} \mathrm{P}<0.001\right.$; Fig. 1B). 
A

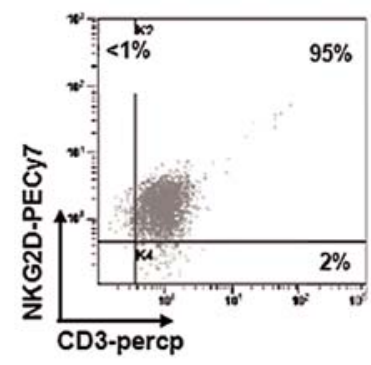

C

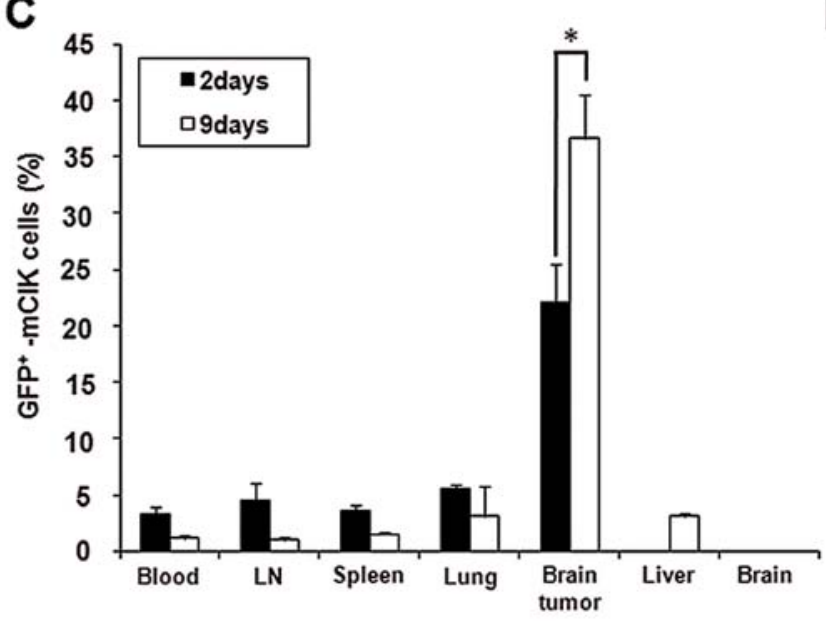

B

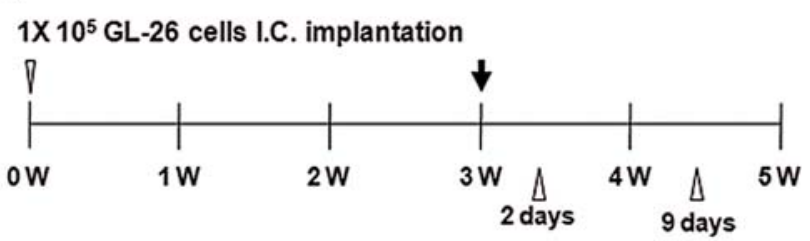

$\downarrow$ : Intravenous injection of GFP+-mCIK cells (in $100 \mu \mathrm{L}$ HBSS)

$\triangle$ : FACS (C) or IHC (D) analysis of GFP+ cells

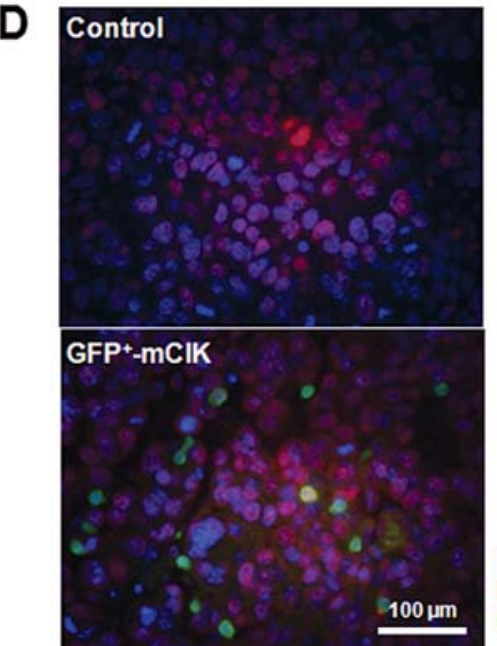

Blue $=\mathrm{DAPI}$

Red $=$ PCNA

Green $=$ GFP

Figure 4. Intravenously-injected mCIK cells infiltrate into the brain tumor in an orthotopic syngenic model. (A) CD3, CD8 and NKG2D expression of cultured mCIK cells were analyzed by flow cytometry. (B) The timeline for the in vivo tracking of intravenously-injected GFP+-mCIK cells in a GBM orthotopic syngenic model. (C) Average percentages of $\mathrm{GFP}^{+}$-mCIK cells in tissue lymphocytes were analyzed by flow cytometry. Black bars = two, white bars = nine days after the administration. Data were expressed as the mean \pm SE. (D) Brain tumors were stained with anti-GFP (green) and anti-PCNA (red) antibody nine days after the administration. Blue = nuclei (DAPI).

In vitro toxicity of hCIK cells against human GBM cells. U-87MG human GBM cells were co-cultured with hCIK cells or fresh hPBMC [effector-to-target $(\mathrm{E}: \mathrm{T})$ ratio=10:1 and $30: 1]$ and in vitro cytotoxic activities of cultured hCIK cells were evaluated by the LDH assay. At E:T ratios of 10:1 and $30: 1$, hCIK cells destroyed $20 \%$, and $42 \%$ of U-87MG cells, respectively $\left({ }^{* * *} \mathrm{P}<0.001\right.$; Fig. 2$)$. In contrast, only $<3 \%$ of cancer cells were destroyed by fresh hPBMC.

In vivo therapeutic effect of hCIK cells against GBM. Next, in vivo therapeutic efficacy of hCIK cells against GBM was determined; $1 \times 10^{5}, 1 \times 10^{6}$ or $1 \times 10^{7} \mathrm{hCIK}$ cells (in $100 \mu \mathrm{l}$ HBSS) were injected intravenously into animals bearing $\mathrm{U}-87 \mathrm{MG}$ tumor in their brains once a week for four weeks (control = HBSS only, each group n=7; Fig. 3A). The tumor volumes were determined one day after the last hCIK cell injection. Treatment with hCIK cells significantly inhibited $\mathrm{U}-87 \mathrm{MG}$ tumor growth in a dose-dependent manner; $1 \times 10^{5}$, $1 \times 10^{6}$ and $1 \times 10^{7}$ groups showed 44,54 and $72 \%$ tumor volume reduction, respectively, compared with the control group $\left({ }^{*} \mathrm{P}<0.05\right.$ vs. control, Fig. 3B). A number of hCIK cells were identified dose-dependently in the tumor bed by specific antihuman CD3 antibody (Fig. 3C), confirming the direct contact between hCIK and GBM cells in the brain.

Infiltration of syngeneic CIK cells into GBM in the brain. Infiltration of hCIK cells into the brain tumor could be a specific phenomenon in the immune-compromised host. To exclude this possibility, we cultured mouse CIK (mCIK) cells from PBMC of GFP transgenic mice (C57BL/6 background) and injected them into the veins of C57BL/6 mice harboring GL26 GBM (GBM cell line originated from C57BL/6) tumor mass in their brains. Cultured $\mathrm{GFP}^{+}$-mCIK cells showed similar surface molecular profiles with hCIK cell population (Fig. 4A; $82 \% \mathrm{CD}^{+} \mathrm{CD}^{+}, 95 \% \mathrm{CD}^{+} \mathrm{NKG}^{+} \mathrm{D}^{+}$). When the injected $\mathrm{GFP}^{+}$-mCIK cells were tracked in blood, brain tumor, and other organs at two days after the injection by flow cytometric analysis $\left(n=5\right.$, Fig. 4B), $\mathrm{GFP}^{+}-\mathrm{mCIK}$ cells were concentrated in brain tumors $\left(\% \mathrm{GFP}^{+}\right.$cells in tissue lymphocytes, Fig. 4C). The ratio further increased nine days after the injection $(n=5)$ compared to day $2\left({ }^{*} \mathrm{P}<0.05\right.$; Fig. $\left.4 C\right)$, suggesting continuous infiltration of CIK cells. $\mathrm{GFP}^{+} \mathrm{mCIK}$ cells in GBM was confirmed by the immunohistochemical method (Fig. 4D).

Immunotherapy using $h C I K$ cells potentiates anti-tumor effect of TMZ. In vivo therapeutic effects of combination treatment of hCIK cells and TMZ were evaluated by tumor mass volume (Fig. 5A). hCIK cells (1x107, in $100 \mu 1 \mathrm{HBSS})$ were injected intravenously into animals bearing U-87MG tumor in their brains once a week for four weeks, either alone or with intraperitoneal daily administration of $2.5 \mathrm{mg} / \mathrm{kg} \mathrm{TMZ}$ (in $100 \mu 1$ saline) from 21 to 25 days after the tumor cell implantation $($ control $=100 \mu 1 \mathrm{HBSS}+$ normal saline, $\mathrm{n}=7$; 
A

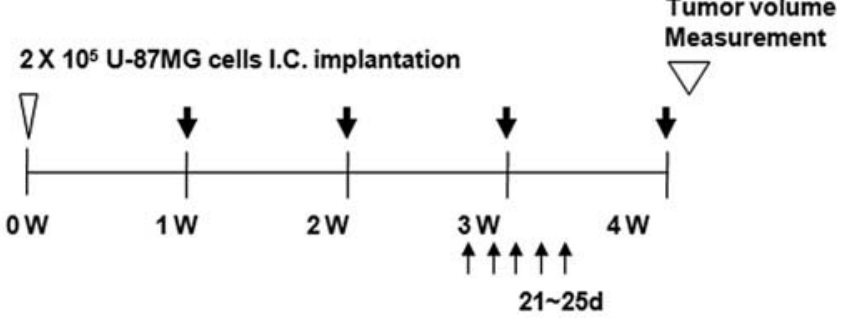

$\downarrow$ : Intravenous injection of $1 \times 10^{7} \mathrm{hCIK}$ cells (in $100 \mu \mathrm{L} \mathrm{HBSS}$ )

$\uparrow$ : Intraperitoneal injection of TMZ (2.5 mg/kg in $100 \mu \mathrm{L}$ saline)

B

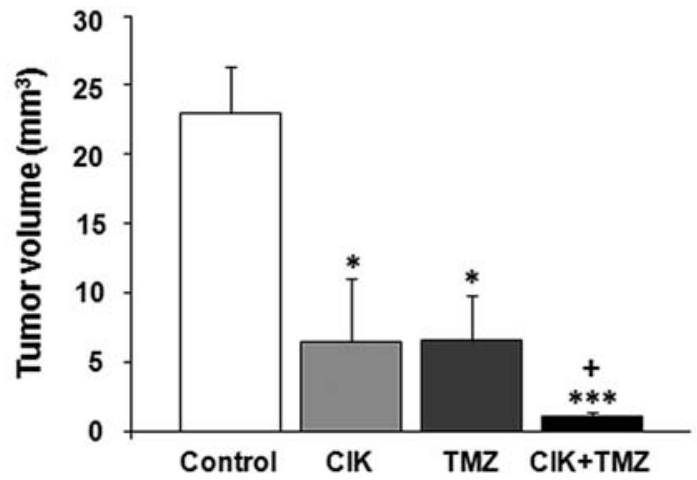

Figure 5. In vivo combination treatment of hCIK cells and TMZ shows additive or synergistic therapeutic effects against GBM. (A) The timeline for the assessment of in vivo therapeutic effects of combinational treatment of hCIK cells and TMZ in an orthotopic xenograft model. (B) hCIK cells and TMZ created additive or synergistic therapeutic effects in the U-87MG human GBM animal model. Data are expressed as the mean $\pm \mathrm{SE}$. ${ }^{*} \mathrm{P}<0.05$ and ${ }^{* * *} \mathrm{P}<0.001$ vs. control, ${ }^{+} \mathrm{P}<0.05$ vs. single agent

hCIK group, n=7; TMZ group, $\mathrm{n}=6$; hCIK + TMZ group, $\mathrm{n}=6$; Fig. 5A). Although either hCIK or TMZ monotherapy showed significant reduction of the tumor volumes $(72 \%$ smaller than that of the control group for both monotherapies, $\left.{ }^{*} \mathrm{P}<0.05\right)$, the combination of hCIK cells and TMZ created additive or synergistic therapeutic effects; hCIK + TMZ group showed $95 \%$ smaller tumor volume than that of control group $\left({ }^{* * *} \mathrm{P}=0.0001\right)$, which was also significantly smaller than those of hCIK and TMZ groups $\left({ }^{+} \mathrm{P}=0.0021\right.$; Fig. $\left.5 \mathrm{~B}\right)$.

In vivo treatment of hCIK cells and/or TMZ decreased tumor cell proliferation and vessel density and increased tumor cell apoptosis. We examined cell proliferation, apoptosis and vessel density by immunostaining for PCNA, by TUNEL assay, and by immunostaining for $\mathrm{CD} 31$, respectively (Fig. 6A). The treatments (hCIK, TMZ, hCIK + TMZ) reduced the numbers of PCNA-positive proliferating cells (per field of view) compared with the control group $(19,13$, and $30 \%$ decrease, respectively, $\mathrm{P}<0.01$; Fig. 6B). The numbers of TUNELpositive apoptotic cells (per field of view) were increased by either hCIK, TMZ, or hCIK + TMZ treatment (1.9-fold, 1.8-fold, and 2.6-fold increase, respectively, $\mathrm{P}<0.01$; Fig. 6B). The numbers of CD31-stained vessels (per field of view) were decreased by either hCIK, TMZ, or hCIK + TMZ treatment $(20,18$, and $32 \%$ decrease, respectively, $\mathrm{P}<0.01$; Fig. 6B). In parallel with additive or synergistic effect of hCIK cells and
TMZ, the hCIK + TMZ group showed significant decrease in the numbers of PCNA-positive and CD31-positive cells and increase in the number of TUNEL-positive cells compared with the hCIK and TMZ group (Fig. 6B).

\section{Discussion}

Recently, CIK cells were reported to inhibit growth of GBM in 1) intratumoral injection of hCIK cells in the orthotopic GBM xenograft models and in 2) intravenous injection of hCIK cells in the subcutaneous GBM xenograft models $(7,8)$. In this study, the therapeutic effects of CIK cells against GBM were tested in a more clinically-relevant setting: U-87MG GBM orthotopic xenograft model and intravenous injection of hCIK cells. hCIK cells, either alone or in combination with TMZ, demonstrated significant treatment effects against GBM, confirming their effects.

TMZ is an indispensable treatment modality for GBM since it is the sole chemotherapeutic agent that has been proved to lengthen the survival of GBM patients (16). Therefore, the therapeutic efficacy of newly-developed immunotherapy need to be compared with TMZ, or combination treatment with TMZ should be investigated to prove the usefulness of the immunotherapy (17). For the first time, we showed that immunotherapy using CIK cells possess similar therapeutic effects to $\mathrm{TMZ}$ and that it can potentiate the effects of TMZ in an additive or synergistic manner. Our results, therefore, increased the clinical relevance of CIK cells further.

We previously reported that TMZ significantly decreased the number of PCNA-positive proliferating tumor cells and increased the number of TUNEL-positive apoptotic tumor cells in an orthotopic GBM xenograft model $(18,19)$. In this study, we found that hCIK cells potentiate the effects of TMZ on the proliferation, apoptosis, and vascularization of GBM cells significantly, which suggest that hCIK cells and TMZ cumulatively enhance the inhibition of cell proliferation and tumor vascularization and the stimulation of apoptosis.

Anti-tumor mechanisms of CIK cells include the secretion of cytotoxic molecules such as granzyme and perforin, the activation of Fas signaling pathway of tumor cells, and the production of multiple cytokines regulating the immune response system $(14,20)$. Therefore, direct interactions between hCIK cells and tumor cells are essential. In the present study, we confirmed the infiltration of CIK cells into GBMs of the brain in both immune-compromised GBM xenograft animal model and immune-competent syngenic GBM animal model. CIK cells introduced systemically were accumulated in the brain tumor preferentially compared with other organs such as blood, lymph node, spleen, lung, liver and normal brain parenchyma. These results strongly suggest that the adoptively transferred CIK cells harbor tumor-trophic activities. Tracking of CIK cells would also be useful to elucidate anti-tumor mechanisms more clearly and to provide a basis for novel modalities with enhanced anti-tumor capacities (21).

Traditionally, hPBMC are incubated in a medium containing IFN- $\gamma$, IL-1ß and/or TNF- $\alpha$ to increase cytotoxicity of CIK cells $(6,22-27)$. However, we optimized the traditional 
A

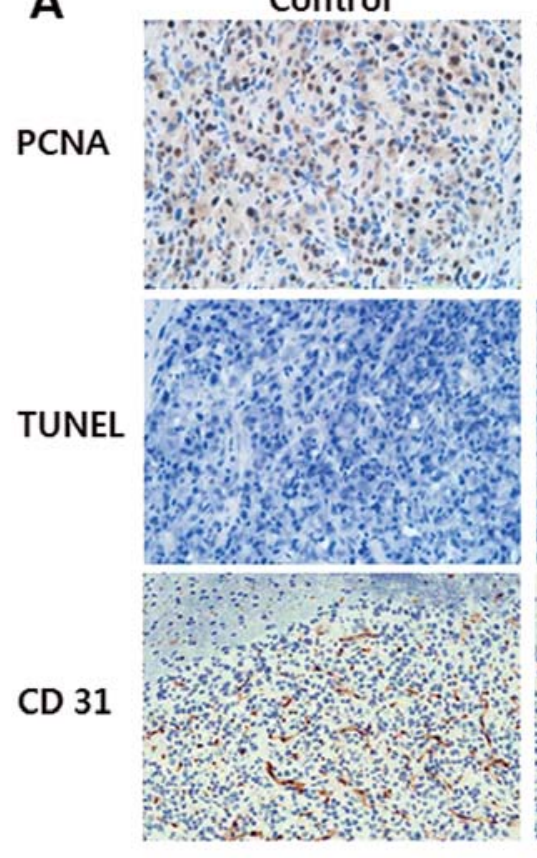

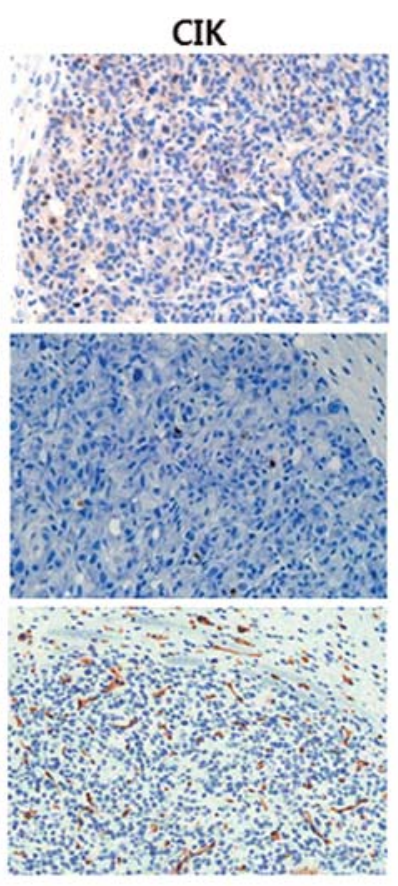

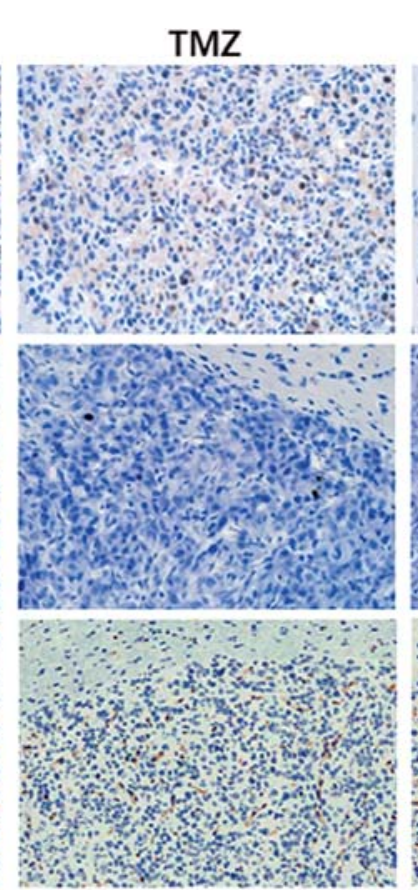

B
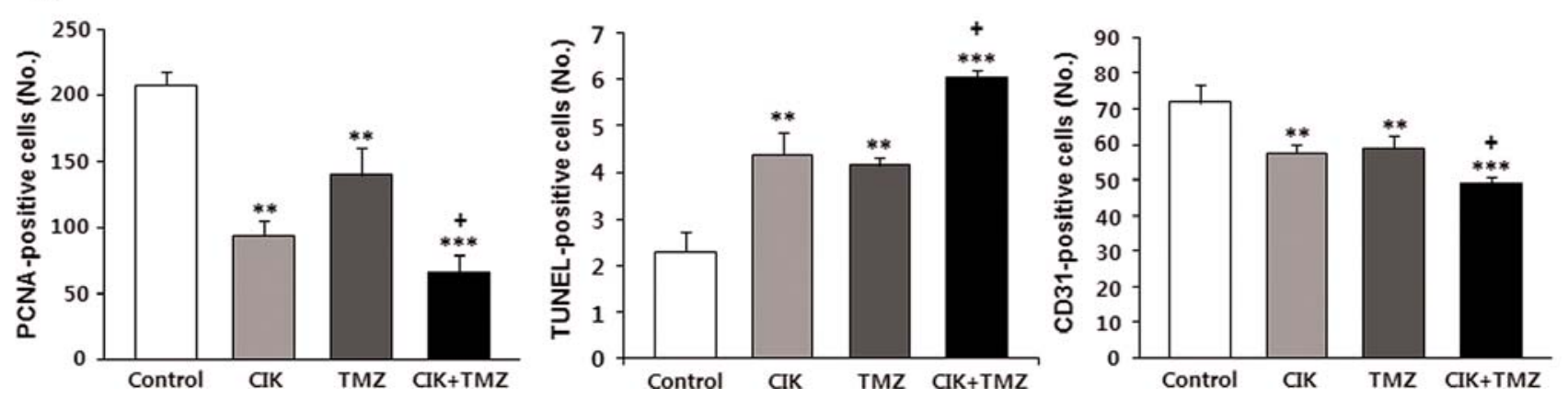

Figure 6. Tumor cell proliferation (PCNA), apoptosis (TUNEL) and vessel density (CD31) are altered by either hCIK, TMZ, or hCIK + TMZ treatment in vivo. (A) Proliferating, apoptotic and endothelial cells were analyzed by anti-PCNA antibody, TUNEL assay and anti-CD31 antibody, respectively, in tumor masses. (B) Numbers of PCNA-, TUNEL-, and CD31-positive cells were calculated and compared (each group, $\mathrm{n}=10$ ). Data are expressed as the mean \pm SE.

${ }^{* *} \mathrm{P}<0.01$ and ${ }^{* * *} \mathrm{P}<0.001$ vs. control, ${ }^{+} \mathrm{P}<0.05$ vs. single agent.

protocol economically and generated hCIK cells without those cytokines. Our optimized protocol also shortened the incubation time from 3-4 weeks to 2 weeks (12). In this study, we generated sufficient $\mathrm{CD} 3{ }^{+} \mathrm{CD} 4-\mathrm{CD} 8{ }^{+} \mathrm{CD} 56^{+}$and $\mathrm{CD}^{+}{ }^{+} \mathrm{CD} 4-\mathrm{CD} 8-\mathrm{CD} 56^{+}$cells with a more economical protocol and confirmed their anti-tumor activities against GBM in vitro and in vivo. These improvements would enable more facile translation to the clinical setting.

LAK cells (in combination with IL-2) eliciting a general systemic immune response in the spleen (21) was previously suggested to be a possible therapy against glioma (28). However, LAK cells have several disadvantages as an immunotherapeutic agent, such as poor cytotoxicity, short in vivo half-life, and numerous side effects $(29,30)$. Regarding specific targeting to tumor site, potent direct cytotoxic effects including both the specific anti-tumor effects of $\mathrm{T}$ cells and the non-MHC-restricted anti-tumor advantage of NK cells and synergistic effects with TMZ, CIK cells could be a more feasible immunotherapeutic agent.

In summary, we provide a clinically-relevant adoptive immunotherapy for GBM using CIK cells. The treatment capability of CIK cells, either alone or in combination with TMZ could be directly translated to clinical trials.

\section{Acknowledgements}

This study was supported by the Korea Research Foundation Grant funded by the Korean Government (KRF-2008-313E00234), a grant from the Korea Healthcare Technology R\&D Project, Ministry for Health and Welfare Affairs, Republic of Korea (A092255), and the Samsung Biomedical Research Institute grant, no. SBRI C-B0-218-1.

\section{References}

1. Curran WJ Jr, Scott CB, Horton J, Nelson JS, Weinstein AS, Fischbach AJ, Chang CH, Rotman M, Asbell SO, Krisch RE, et al: Recursive partitioning analysis of prognostic factors in three Radiation Therapy Oncology Group malignant glioma trials. J Natl Cancer Inst 85: 704-710, 1993.

2. Yoffey JM and Courtice FC: Lymphatics, Lymph, and the Lymphomyeloid Complex. Academic Press, London, New York, 1970. 
3. Fenstermaker RA and Ciesielski MJ: Immunotherapeutic strategies for malignant glioma. Cancer Control 11: 181-191, 2004.

4. Baker J, Verneris MR, Ito M, Shizuru JA and Negrin RS: Expansion of cytolytic CD8(+) natural killer T cells with limited capacity for graft-versus-host disease induction due to interferon gamma production. Blood 97: 2923-2931, 2001

5. Lu PH and Negrin RS: A novel population of expanded human $\mathrm{CD}^{+}{ }^{+} \mathrm{CD} 56^{+}$cells derived from $\mathrm{T}$ cells with potent in vivo antitumor activity in mice with severe combined immuno-deficiency. J Immunol 153: 1687-1696, 1994.

6. Alvarnas JC, Linn YC, Hope EG and Negrin RS: Expansion of cytotoxic $\mathrm{CD}^{+} \mathrm{CD}^{+} 6^{+}$cells from peripheral blood progenitor cells of patients undergoing autologous hematopoietic cell transplantation. Biol Blood Marrow Transplant 7: 216-222, 2001.

7. Wang P, Yu JP, Gao SY, An XM, Ren XB, Wang XG and Li WL: Experimental study on the treatment of intracerebral glioma xenograft with human cytokine-induced killer cells. Cell Immunol 253: 59-65, 2008.

8. Kim HM, Kang JS, Lim J, Kim JY, Kim YJ, Lee SJ, Song S, Hong JT, Kim Y and Han SB: Antitumor activity of cytokineinduced killer cells in nude mouse xenograft model. Arch Pharm Res 32: 781-787, 2009.

9. Takayama T, Sekine T, Makuuchi M, Yamasaki S, Kosuge T, Yamamoto J, Shimada K, Sakamoto M, Hirohashi S, Ohashi Y and Kakizoe T: Adoptive immunotherapy to lower postsurgical recurrence rates of hepatocellular carcinoma: a randomised trial. Lancet 356: 802-807, 2000.

10. Kim HM, Kang JS, Lim J, Park SK, Lee K, Yoon YD, Lee CW Lee KH, Han G, Yang KH, Kim YJ, Kim Y and Han SB: Inhibition of human ovarian tumor growth by cytokine-induced killer cells. Arch Pharm Res 30: 1464-1470, 2007.

11. Kim HM, Lim J, Park SK, Kang JS, Lee K, Lee CW, Lee KH, Yun MJ, Yang KH, Han G, Kwon SW, Kim Y and Han SB: Antitumor activity of cytokine-induced killer cells against human lung cancer. Int Immunopharmacol 7: 1802-1807, 2007.

12. Kim HM, Lim J, Yoon YD, Ahn JM, Kang JS, Lee K, Park SK Jeong YJ, Kim JM, Han G, Yang KH, Kim YJ, Kim Y and Han SB: Anti-tumor activity of ex vivo expanded cytokineinduced killer cells against human hepatocellular carcinoma. Int Immunopharmacol 7: 1793-1801, 2007.

13. Schaefer BC, Schaefer ML, Kappler JW, Marrack P and Kedl RM: Observation of antigen-dependent $\mathrm{CD}^{+} \mathrm{T}$-cell/dendritic cell interactions in vivo. Cell Immunol 214: 110-122, 2001

14. Li H, Yu JP, Cao S, Wei F, Zhang P, An XM, Huang ZT and Ren XB: $\mathrm{CD}^{+} \mathrm{CD} 25^{+}$regulatory $\mathrm{T}$ cells decreased the antitumor activity of cytokine-induced killer (CIK) cells of lung cancer patients. J Clin Immunol 27: 317-326, 2007.

15. Nam DH, Park K, Park C, Im YH, Kim MH, Lee S, Hong SC, Shin HJ, Kim JH, Eoh W and McDonnell TJ: Intracranial inhibition of glioma cell growth by cyclooxygenase- 2 inhibitor celecoxib. Oncol Rep 11: 263-268, 2004.

16. Chang SM, Lamborn KR, Malec M, Larson D, Wara W, Sneed P, Rabbitt J, Page M, Nicholas MK and Prados MD: Phase II study of temozolomide and thalidomide with radiation therapy for newly diagnosed glioblastoma multiforme. Int J Radiat Oncol Biol Phys 60: 353-357, 2004.

17. Carpentier AF and Meng Y: Recent advances in immunotherapy for human glioma. Curr Opin Oncol 18: 631-636, 2006.
18. Son MJ, Kim JS, Kim MH, Song HS, Kim JT, Kim H, Shin T, Jeon HJ, Lee DS, Park SY, Kim YJ, Kim JH and Nam DH: Combination treatment with temozolomide and thalidomide inhibits tumor growth and angiogenesis in an orthotopic glioma model. Int J Oncol 28: 53-59, 2006.

19. Kim JT, Kim JS, Ko KW, Kong DS, Kang CM, Kim MH Son MJ, Song HS, Shin HJ, Lee DS, Eoh W and Nam DH: Metronomic treatment of temozolomide inhibits tumor cell growth through reduction of angiogenesis and augmentation of apoptosis in orthotopic models of gliomas. Oncol Rep 16: 33-39, 2006.

20. Ren X, Yu J, Liu H, Zhang P, An X, Zhang N and Hao X: Th1 bias in PBMC induced by multicycles of auto-CIKs infusion in malignant solid tumor patients. Cancer Biother Radiopharm 21: 22-33, 2006.

21. Takashima K, Fujiwara H, Inada S, Atsuji K, Araki Y, Kubota T and Yamagishi $\mathrm{H}$ : Tracking of green fluorescent protein (GFP)labeled LAK cells in mice carrying B16 melanoma metastases. Anticancer Res 26: 3327-3332, 2006

22. Leemhuis T, Wells S, Scheffold C, Edinger M and Negrin RS: A phase I trial of autologous cytokine-induced killer cells for the treatment of relapsed Hodgkin disease and non-Hodgkin lymphoma. Biol Blood Marrow Transplant 11: 181-187, 2005.

23. Thorne SH, Negrin RS and Contag CH: Synergistic antitumor effects of immune cell-viral biotherapy. Science 311: 1780-1784, 2006.

24. Verneris MR, Arshi A, Edinger M, Kornacker M, Natkunam Y, Karami M, Cao YA, Marina N, Contag CH and Negrin RS: Low levels of Her2/neu expressed by Ewing's family tumor cell lines can redirect cytokine-induced killer cells. Clin Cancer Res 11: 4561-4570, 2005.

25. Chan JK, Hamilton CA, Cheung MK, Karimi M, Baker J, Gall JM, Schulz S, Thorne SH, Teng NN, Contag CH, Lum LG and Negrin RS: Enhanced killing of primary ovarian cancer by retargeting autologous cytokine-induced killer cells with bispecific antibodies: a preclinical study. Clin Cancer Res 12: 1859-1867, 2006.

26. Kornacker M, Moldenhauer G, Herbst M, Weilguni E, TitaNwa F, Harter C, Hensel M and Ho AD: Cytokine-induced killer cells against autologous CLL: direct cytotoxic effects and induction of immune accessory molecules by interferon-gamma. Int J Cancer 119: 1377-1382, 2006

27. Verneris MR, Kornacker M, Mailander V and Negrin RS: Resistance of ex vivo expanded $\mathrm{CD} 3^{+} \mathrm{CD} 56^{+} \mathrm{T}$ cells to Fasmediated apoptosis. Cancer Immunol Immunother 49: 335-345, 2000.

28. Jacobs SK, Wilson DJ, Kornblith PL and Grimm EA: In vitro killing of human glioblastoma by interleukin-2-activated autologous lymphocytes. J Neurosurg 64: 114-117, 1986.

29. Dillman RO, Duma CM, Schiltz PM, DePriest C, Ellis RA, Okamoto K, Beutel LD, De Leon C and Chico S: Intracavitary placement of autologous lymphokine-activated killer (LAK) cells after resection of recurrent glioblastoma. J Immunother 27: 398-404, 2004.

30. Hayes RL, Koslow M, Hiesiger EM, Hymes KB, Hochster HS, Moore EJ, Pierz DM, Chen DK, Budzilovich GN and Ransohoff J: Improved long term survival after intracavitary interleukin-2 and lymphokine-activated killer cells for adults with recurrent malignant glioma. Cancer 76: 840-852, 1995. 